\title{
COMO AS PESSOAS PERCEBEM O PSICÓLOGO: UM ESTUDO EXPLORATÓRIO ${ }^{1}$
}

\author{
Marcilio Lira de Souza Filho ${ }^{2}$ \\ Universidade Federal de Pernambuco \\ Josevânia da Silva Cruz de Oliveira \\ Flávio Lúcio Almeida Lima \\ Universidade Federal da Paraíba
}

\begin{abstract}
Resumo: Este estudo buscou realizar um levantamento de elementos que indiquem como o psicólogo é percebido. Participaram pessoas entrevistadas na cidade de João Pessoa (PB), distribuídas em três grupos, a saber, pessoas da população geral $(n=42)$, estudantes de Enfermagem $(n=43)$ e de Psicologia $(n=52)$. Todas se submeteram a uma associação livre de palavras após ouvirem o termo psicólogo. Os resultados demonstraram que todos os grupos indicaram perceber o psicólogo como profissional promotor de saúde mental e proporcionador de auxílio psicológico. Particularmente, na população geral houve pessoas que nada souberam declarar. Os estudantes de Enfermagem mostraram uma percepção mais adequada das práticas do psicólogo quando comparados com a população geral. Apenas os estudantes de Psicologia demonstraram uma atenção a aspectos humanitários da prática profissional do psicólogo. Discutem-se os resultados buscando vincular a percepção de cada grupo às circunstâncias e aspectos predominantes de cada um deles.
\end{abstract}

Palavras-chave: Psicologia no Brasil; psicólogo; profissão.

\section{HOW DO PEOPLE PERCEIVE THE PSYCHOLOGIST: AN EXPLORATORY STUDY}

Abstract: This study tried to do a survey of some elements that indicate how the psychologist is perceived. The participants were people from João Pessoa (PB), Brazil, interviewed and divided in three groups: ordinary people $(n=42)$, Nursery students $(n=43)$ and Psychology students $(n=52)$. All of them were submitted to a word-free association when they heard the word psychologist. The results showed that in all groups the psychologist was perceived as a professional that worked into mental health and as a promoter of psychological care. Some individuals of ordinary people group could not answer it. The Nursery students approached to a realistic practice of the psychologist in comparison to ordinary people group. Only the psychology students showed special attention to humanitarian aspects of the psychologist care. The results were debated from a link among the perception of each group and the main social aspects of them.

Key words: Psychology in Brazil; psychologist; profession.

\section{Introdução}

Desde o final do século XIX, quando foi inaugurada como ciência, a Psicologia vem conquistando o seu espaço enquanto campo de estudo e atuação. A fundação do primeiro laboratório de Psicologia Experimental de Wilhelm Wundt, em 1879, na Alemanha, significou o estopim do desenvolvimento científico da Psicologia. Segundo Castro (1999), logo após Wundt, muitos outros estudiosos contribuíram para o crescimento do conhecimento em Psicologia. Perce-

\footnotetext{
${ }^{1}$ Recebido em 30/03/06 e aceito para publicação em 10/10/06.

${ }^{2}$ Endereço para correpondência: Marcilio Lira de Souza Filho, Rua Enf. Ana Maria Barbosa de Almeida, 187, Jardim Cidade Universitária, CEP: 58052-270, João Pessoa-PB, E-mail: liradesouza@yahoo.com.br
}

be-se que a herança deixada por esse passado produtivo é uma multiplicidade de modelos teóricos e metodológicos que permanecem até hoje e fundamentam tanto a ciência quanto a atuação profissional na área.

A história da atuação profissional no Brasil surge concomitante com a Psicologia científica; antes disso inexistia aqui o reconhecimento da Psicologia como prática com terminologia e conhecimento definido. Pereira e Neto (2003) sugerem três períodos sob os quais estaria dividida a história da profissão no Brasil. O primeiro, denominado pré-profissional, ocorreu até o final do século XIX quando a Psi- 


\section{Marcilio Lira de Souza Filho}

cologia não era uma prática regulamentada; o segundo corresponde à profissionalização, no qual ocorre a institucionalização e regulamentação da profissão, tal período aconteceu entre 1890 e 1975; e o terceiro, a partir de 1975, corresponde ao período profissional, momento em que a profissão foi se organizando e estabelecendo.

A formação profissional do psicólogo foi institucionalizada através da Portaria 272, referente ao Decreto-Lei 9092, de 1946. No que tange à inserção no mercado de trabalho, a atuação do psicólogo se iniciou nas áreas da educação e do trabalho entre os anos 1940 e 1950. Em 27 de agosto de 1962 a Lei $\mathrm{n}^{\circ} 4.119$ regulamentou a profissão de psicólogo e, nesse mesmo ano, o Parecer 403 do Conselho Federal de Educação definiu o currículo mínimo e duração do curso superior de Psicologia. Tais fatos históricos serviram como grande apoio para a abertura do mercado aos psicólogos (Netto, 2004).

Devido ao crescimento dos cursos universitários e à busca da população por serviços psicológicos, a partir dos anos 70, o número de profissionais formados em Psicologia se acentua. Entre 1970 e 1980, três áreas da Psicologia se destacavam: educação, trabalho e clínica, sendo esta última a de maior procura dos profissionais (Pereira \& Neto, 2003). Atualmente, contudo, o espectro de abrangência profissional do psicólogo é bastante amplo e compreende uma vasta gama de áreas de atuação, entre elas podem ser citadas as clínicas particulares, escolas, creches, empresas, hospitais, postos de saúde, comunidades, setores judiciários, penitenciárias, equipes desportivas, departamentos de trânsito e outras.

A consolidação da entrada do psicólogo no mercado de trabalho, no contexto nacional, gerou a necessidade de avaliar essa profissão, tanto em termos da organização profissional, quanto no tocante à forma como essa prática vinha sendo percebida. Isso tem motivado a realização de pesquisas tanto na primeira direção (CFP, 2004; Mello, 1975; Yamamoto, Dantas, Costa, Alverga, Seixas \& Oliveira, 2003), quanto na segunda (Bettoi \& Simão, 2002; Gomes, Teixeira, Crescente, Fachel, Sehn \& Klarmann, 1996; Santos, 1989; Weber, Rickli \& Liviski, 1994).

Segundo um recente levantamento realizado pelo Conselho Federal de Psicologia (CFP, 2004), a profissão de psicólogo no Brasil é, predominantemente, feminina $(91 \%)$ e jovem $(65 \%$ estava na faixa etária compreendida entre 26 e 45 anos); têm-se como atuação principal a Psicologia Clínica com atendimento individual ou em grupo (55\%) e dispõe-se, prioritariamente, como local de trabalho as clínicas particulares $(41 \%)$. Os resultados apresentados nos estudos anteriores de Mello (1975) e Yamamoto e cols. (2003) seguem basicamente esta mesma direção.

A marcante preferência pela área clínica, acima descrita, é verificada também entre alunos de graduação em Psicologia. O estudo de Magalhães, Straliotto, Keller e Gomes (2001), realizado com estudantes de Psicologia do primeiro ano da graduação, demonstrou que a escolha da profissão é acompanhada, primeiramente, por um sentimento altruísta de ajuda ao próximo, seguido da busca por um crescimento pessoal, encanto pelo conhecimento psicológico e competência profissional. Destarte, a preferência pela área clínica estaria relacionada a esse desejo de "ajuda ao próximo", de "uma relação direta, íntima e prolongada", uma vez que ela possibilitaria tal relação. Ademais, as instituições e a comunidade representariam, na opinião desses alunos, locais onde não seria possível o desenvolvimento de uma atuação "profunda".

Mello (1975) já ressaltava que a relevância da presente questão não estaria em se criticar a preferência dos profissionais e alunos pela clínica, mas em verificar quais as variáveis que estariam imbricadas nessa orientação da profissão e, a posteriori, quais seriam seus efeitos nas relações dessa profissão com a sociedade. Ademais, o que tem sido observado, mais especificamente a partir da década de 80 , é o crescimento de uma demanda por profissionais de Psicologia nos serviços públicos, exigindo uma prática profissional diversificada uma vez que a população a ser atendida tem características diferentes daquelas nas quais, historicamente, os psicólogos lidavam (Andrade \& Morato, 2004).

Ainda a esse respeito, Dimenstein (2000) aponta a existência de uma cultura do profissional da Psicologia no Brasil, afirmando que essa tem se caracterizado por um modelo de subjetividade decorrente do desenvolvimento de um ideário individualista, reforçado pela difusão da Psicanálise na classe média 
urbana. A presença de uma ideologia individualista e de um modelo clínico de atuação (privada) na cultura profissional do psicólogo gera conseqüências na sua prática quando é impelido a atuar no setor público (postos de saúde e ambulatórios, por exemplo) uma vez que esse modelo de atuação é transportado para esse contexto. Em decorrência disso, Dimenstein (2000) menciona o abandono dos tratamentos, uma baixa eficácia da terapêutica, uma "psicologização dos problemas sociais" e uma "hierarquização da clientela".

No que tange à forma como o psicólogo é percebido, Santos (1989), analisando uma amostra de calouros de um curso de formação em Psicologia da cidade de São Paulo, apresentou a seus participantes a pergunta "O que faz um psicólogo na sua opinião?". Seus resultados revelaram um insuficiente e desordenado conhecimento acerca das diversas áreas de atuação em Psicologia. No geral, o que se observou foi uma expressiva predominância da menção à área de atuação clínica e do psicólogo percebido enquanto um profissional liberal atuando em consultórios particulares; ele possuiria um "conhecimento teórico eclético e profundo" sobre o ser humano e tal conhecimento seria o responsável ou o elemento capacitador que lhe permitiria ajudar, aconselhar e orientar as pessoas.

Nesta mesma direção, Weber e cols (1994) também comentam que a representação social que o público leigo tem do psicólogo e da Psicologia apresenta limitações e equívocos, em boa parte, devido à maneira como os profissionais da área viriam atuando. Estes vieses estariam vinculados, mormente, entre outros fatores, à formação acadêmica em Psicologia.

Em um outro estudo, Bettoi e Simão (2002) contaram com a participação dos alunos de uma disciplina de Psicologia Geral e de profissionais para verificar as concepções existentes acerca do psicólogo. De modo geral, os alunos concebiam o psicólogo como alguém que é definido por seus atributos pessoais (aspectos morais e éticos), ao passo que a prática profissional e o benefício social dessa prática eram enfatizados em segundo plano. Os profissionais, por sua vez, também mencionaram a necessidade de atributos pessoais para que o psicólogo possa ser bem sucedido; entre esses figuram a postura éti- ca, a maturidade, a humildade, entre outros. Ainda, na amostra de profissionais, observou-se maior ênfase nos aspectos valorativo e moral das qualidades pessoais do psicólogo do que nos racionais. Todavia, as concepções dos alunos, ao final da disciplina, foram relativamente equivalentes nesses dois aspectos.

Gomes e cols. (1996), por sua vez, analisaram as crenças de estudantes universitários de Psicologia e de outros cursos sobre a psicoterapia e o psicólogo. Utilizando uma escala psicométrica, identificaram que os estudantes de Psicologia eram mais favoráveis, em comparação com os universitários de outros cursos, à psicoterapia e que, a partir dela, os clientes poderiam obter benefícios. Por seu turno, os estudantes de outros cursos, mais do que os de Psicologia, atribuíam um papel de maior diretividade à figura do psicólogo. Os autores comentam que, apesar de a Psicologia estar cada vez mais popular, o público leigo ainda permanece com uma imagem não correspondente com a que o psicólogo tem de si mesmo e de sua prática. Segundo esses autores, os psicólogos não aceitariam para si o papel, atribuído pelos leigos, de alguém que "sabe" e que, com base nesse "saber", instrui ou orienta os seus pacientes no sentido de resolverem suas dificuldades. Pelo contrário, esses profissionais parecem constituir um conjunto de crenças que justificam suas práticas desvinculadas de um caráter mais orientador ou instrutor. Desta discrepância de expectativas resultaria uma baixa aderência aos tratamentos.

Verificar, pois, como as pessoas percebem uma prática profissional se faz necessário em qualquer área de atuação uma vez que possibilita o reconhecimento de aspectos positivos e de debilidades dessa prática, seja no seu processo de formação acadêmica, ou no próprio exercício dessa mesma prática e ainda, na trajetória histórico-epistemológica de sua constituição enquanto disciplina. Nesta direção, a presente pesquisa, assumindo um caráter exploratório, objetivou fazer um levantamento de elementos que apontem como a figura do psicólogo é percebida não por um único grupo, mas sim por diferentes grupos, especificamente por pessoas da população geral, estudantes de Enfermagem e de Psicologia, buscando vincular a percepção de cada grupo às circunstâncias e aspectos predominantes de cada um deles. 
A escolha desses grupos não foi aleatória. Primeiramente, verificar a percepção de pessoas da população geral se fez importante tendo em vista que este grupo constitui o principal público-alvo ao qual se destina a prática profissional do psicólogo, sendo o conhecimento da percepção de tal população ponto fundamental para uma otimizada atuação desse profissional. Os estudantes de Enfermagem, por sua vez, mais do que as pessoas da comunidade geral têm uma proximidade maior com os elementos do universo da Psicologia por compartilharem uma realidade acadêmico-científica análoga. Consequentemente, isso deverá permitir identificar se essa proximidade contribuiria com uma percepção mais completa ou abrangente da Psicologia. Finalmente, os estudantes de Psicologia, por se tratarem de futuros profissionais e dada a sua contingência acadêmica, têm uma estreita ligação com os conteúdos teóricos e possibilidades práticas da área. Isso, contudo, seria suficiente para ter uma visão completa ou não-estereotipada da Psicologia? Enfim, verificar a forma como psicólogo e sua prática são percebidos mostra-se extremamente relevante uma vez que tais percepções perpassam a relação existente entre o profissional e a clientela atendida. Assim, espera-se que este estudo possa levar a melhor compreensão de como o papel do psicólogo é percebido pela sociedade.

\section{Método}

\section{Amostra}

Contou-se, neste estudo, com a participação de três grupos distintos. O primeiro foi composto por 42 pessoas da população geral entrevistadas nas ruas da cidade de João Pessoa (Paraíba). Suas idades variavam de 18 a 74 anos $(M=30,9 ; D P=10,9)$. $\mathrm{O}$ nível de escolaridade predominante foi o Ensino Médio completo $(59,5 \%)$. No segundo grupo foram reunidos 43 estudantes do curso de Enfermagem da UFPB, a maioria do sexo feminino $(84,2 \%)$, com idades variando entre 19 e 25 anos $(M=21,9 ; D P=$ $1,53)$ e que já haviam cursado ao menos a metade de sua graduação. Finalmente, o terceiro grupo foi composto por 52 estudantes de Psicologia da UFPB, sendo a maioria também do sexo feminino $(73,1 \%)$ e com suas idades variando entre 19 e 39 anos $(M=$ $22,6 ; D P=3,57)$, tal como os estudantes de Enfermagem, neste grupo todos os alunos eram vetera- nos. Dado o caráter exploratório deste estudo, todos esses grupos compõem amostras do tipo nãoprobabilística, selecionadas de forma acidental ou por conveniência.

\section{Procedimento de Coleta}

Por se tratar de grupos distintos, cujo acesso envolveria diferentes estratégias, o método de coleta variou em função do grupo a ser entrevistado; não obstante, basicamente, todos responderam a um teste de associação livre de palavras. Os participantes foram informados sobre o caráter sigiloso com que suas respostas seriam tratadas e que a participação no estudo era completamente voluntária.

No caso das pessoas da população geral, aplicadores treinados de ambos os sexos abordavam individualmente cada pessoa nas ruas da cidade e o convidava a participar da pesquisa. Uma vez recebido o consentimento em colaborar com o estudo, o aplicador pedia para que, logo após ser falada uma palavra, o respondente dissesse em seguida as três primeiras palavras que lhe viessem à cabeça. Após dar essa instrução, ele falava a palavra-estímulo $P$ sicólogo e registrava as palavras proferidas pelos respondentes. Ademais, foi registrado o sexo dos respondentes e solicitado que informassem sua idade e grau de escolaridade.

Diferentemente, no caso dos estudantes universitários, tanto do curso de Enfermagem quanto do de Psicologia, as aplicações foram feitas num contexto coletivo de sala de aula. Foram entregues folhas em branco a cada um dos participantes e dadas instruções semelhantes às das pessoas da população geral. A diferença, neste caso, é que os próprios participantes escreviam as suas respostas. Foi também pedido que informassem seu sexo, idade, curso e período acadêmico em que se encontravam.

\section{Análise dos Dados}

Após coletados, os dados foram tabulados no pacote estatístico STATISCA versão 6.0 para que fossem realizadas Clusters Analysis, a fim de identificar possíveis reuniões entre os elementos surgidos nas associações livres. A tabulação foi feita de modo a que cada palavra dita pelos respondentes fosse tomada como uma variável. Quando um participante havia apresentado a palavra registrava-se no banco de dados essa presença com o número 1 e nas pala- 
vras que não haviam sido mencionadas registravase 0. Desse modo foram criados três bancos (um para cada grupo) com variáveis do tipo dicotômica ( $\mathbf{1}$ = disse a palavra e $\mathbf{0}=$ não disse a palavra). A partir desses bancos foram efetuadas as análises. Os resultados das análises serão expostos no tópico a seguir.

\section{Resultados}

Para realizar o levantamento dos elementos que indicam como o psicólogo é percebido por diversos grupos foi utilizada a técnica da associação livre de palavras com os participantes. Todas as suas respostas foram submetidas a uma Cluster Analysis. Esta é uma técnica estatística multivariada que envolve um conjunto de procedimentos que visa agrupar e discriminar variáveis com base na distância entre elas. $\mathrm{Na}$ construção de conglomerados de variáveis (no caso deste estudo cada palavra dita pelos participantes correspondeu a uma variável) objetiva-se que variáveis próximas fiquem em um mesmo grupo e as mais distantes fiquem em grupos separados. Neste sentido, esta análise possibilita a composição de categorias de palavras, com a reunião de elementos semelhantes, de forma empírica, sem que se recorra a métodos intuitivos ou subjetivos para reunião de elementos próximos.

A distância entre as variáveis é calculada com base em matriz de distâncias, que, no presente estudo foi calculada em função da métrica City-Block (Manhattan). Foi também utilizada a regra de almagamação de Ward, que determina quando dois agrupamentos serão unidos. Os resultados dessa análise podem ser representados graficamente por meio de um dendrograma (gráfico em formato de árvore). Neste gráfico, a maior relação entre as variáveis é expressa por maior proximidade entre elas, ou seja, quanto mais próximas entre si mais relacionadas e quanto mais distantes estiverem umas das outras menos relacionadas estarão. O ponto de corte para composição das categorias pode ser arbitrário na escala do grau da amalgamação, escolhido em função da interpretabilidade dos dados. Ainda com relação às categorias, compete indicar que, dado o tamanho da amostra, estas não foram detalhadas ou ordenadas em termos de suas freqüências. Limitou-se aqui a somente identificar que elementos (palavras) apa- reciam e como estes se agrupavam, formando categorias com sentido comum.

Para a análise em cada grupo aqui considerando (pessoas da população geral, estudantes de Enfermagem e Psicologia) foram introduzidas apenas aquelas palavras que tiveram freqüência superior a uma unidade. Tendo essas palavras sido identificadas, elas foram submetidas à Cluster Analysis. Os dendrogramas resultantes dessas análises são apresentadas em seguida para cada um dos grupos.

Primeiramente foram analisadas as respostas dadas pelos participantes da população geral. Entraram para compor esta análise 15 palavras. Como se pode ver no Gráfico 1, considerando-se um grau de amalgamação de 6,0 , foi possível organizar as palavras em seis categorias.

Gráfico 1. Dendrograma dos Agrupamentos das Palavras que Expressam a Percepção do Psicólogo pela População Geral.

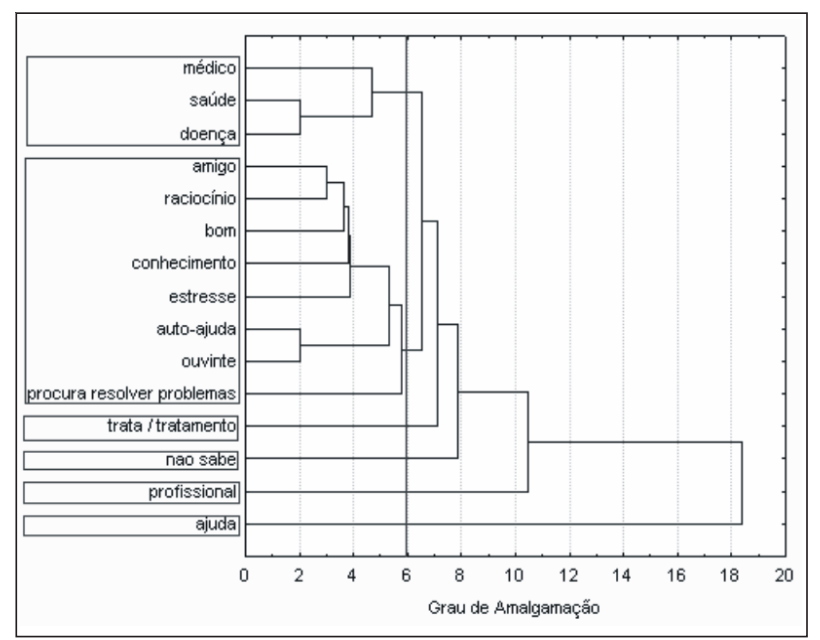

Na primeira categoria, foram reunidos os termos médico, saúde e doença, em função disso denominou-se essa categoria como "Modelo Médico" por reunir elementos que são predominantemente característicos da área médica. A segunda categoria congregou o maior número de palavras. Foram reunidos os termos amigo, raciocínio, bom, conhecimento, estresse, auto-ajuda, ouvinte e procura resolver problemas. Denominou-se a esta categoria de "Elementos Relacionais Gerais Difusos", por 
reunir atributos e outros elementos relacionados vagamente com a figura do psicólogo. Ademais, foram observados elementos que emergiram isoladamente, a saber, "Trata / Tratamento", "Não Sabe" (respostas das pessoas que indicaram nada saber sobre o psicólogo) "Profissional" e "Ajuda".

Em seguida, foram analisadas as respostas dos estudantes de Enfermagem. Para este grupo contouse com 21 palavras que, levando em consideração um grau de amalgamação de 7,2, foram organizadas em oito categorias, como podem ser vistas no Gráfico 2 a seguir.

Gráfico 2. Dendrograma dos Agrupamentos das Palavras que Expressam a Percepção do Psicólogo pelos Estudantes de Enfermagem.

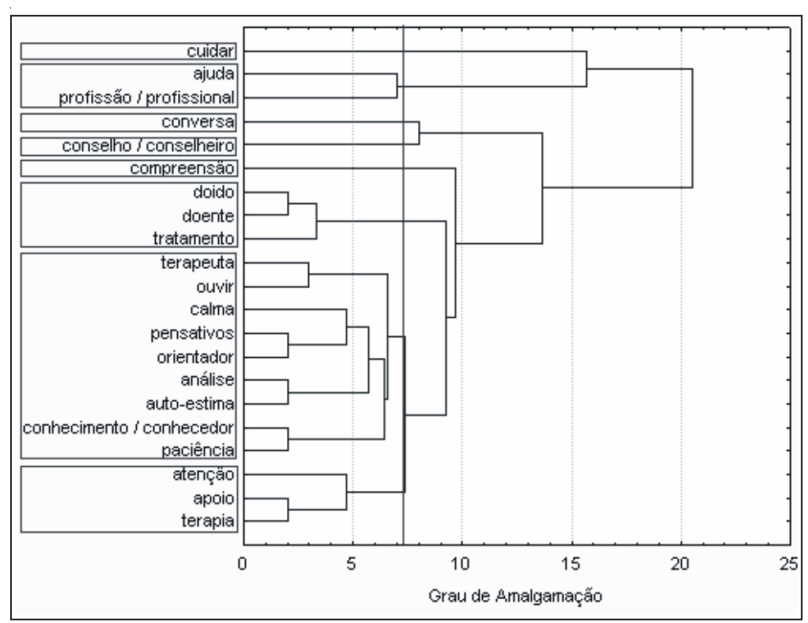

Dos agrupamentos, o primeiro reuniu os termos ajuda e profissão / profissional, neste sentido essa categoria foi denominada de "Auxilio Profissional" por seus termos fazerem referência a um oficio ou atuação profissional que tem como objetivo eminente oferecer uma ajuda psicológica qualificada. O segundo agrupamento reuniu as palavras doido, doente e tratamento, por essa razão foi denominado de "Modelo Psiquiátrico", tendo em vista que tais termos evocam elementos do meio médico, especificamente, da psiquiatria. $\mathrm{O}$ terceiro agrupamento foi o maior e reuniu os termos terapeuta, ouvir, calma, pensativos, orientador, análise, auto-estima, conhecimento/conhecedor e paciência. Este foi chamado de "Elementos Relacionais Gerais", pois agregou palavras que, no geral, qualificavam a prática profissional do psicólogo. Esta categoria difere da observada na população geral na medida em que englobou termos mais precisos, menos vagos. $\mathrm{O}$ último agrupamento congregou as palavras atenção, apoio e terapia. Foi nomeado como "Suporte Psicológico" posto que envolve expressões relativas a prestação de um apoio psicológico. Por fim, também foram constatados termos que emergiram isoladamente, tais como "Cuidar", "Conversa", "Conselho / Conselheiro" e "Compreensão".

Por fim, na amostra de estudantes de Psicologia 23 palavras foram consideradas para análise, as quais, tomando um grau de amalgamação de 7,8 , foram organizadas em nove categorias, como pode ser visto logo abaixo no Gráfico 3.

Gráfico 3. Dendrograma dos Agrupamentos das Palavras que Expressam a Percepção do Psicólogo pelos Estudantes de Psicologia.

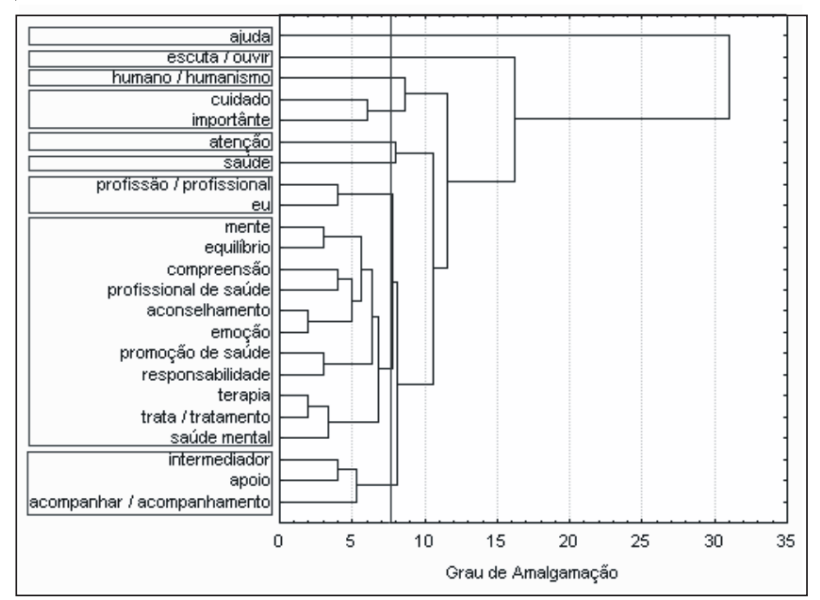

No primeiro agrupamento, estavam presentes as palavras cuidado e importante. Este agrupamento foi denominado de "Relevância", uma vez que enfatiza o valor dado ao cuidado oferecido pelo psicólogo. No segundo agrupamento, reuniram-se profissão / profissional e eu denotando uma "Identificação Profissional” com a Psicologia. O terceiro agrupamento, o mais numeroso de todos, combinou os termos mente, equilibrio, compreensão, profissional de saúde, aconselhamento, emoção, promoção de saúde, responsabilidade, terapia, trata / tratamento e saúde mental. Ele foi chamado de "Saúde Mental" porque agregou termos relativos à 
promoção, por parte do psicólogo, da saúde psicológica. O quarto agrupamento combinou intermediador, apoio e acompanhar / acompanhamento, expressando o "Suporte Psicológico" fornecido pelo psicólogo. Isoladamente observaram-se os termos "Ajuda", "Escuta / Ouvir", "humano / humanismo", "Atenção" e "Saúde".

Como pôde ser notado, os três grupos possuem entre si diferenças e similaridades quanto à percepção que têm do psicólogo. No tópico seguinte, esses achados serão discutidos, buscando-se analisar que elementos estão envolvidos no desenvolvimento e manutenção dessa percepção.

\section{Discussão}

O presente estudo buscou identificar elementos que apontem como a figura do psicólogo é percebida por diferentes grupos, particularmente, por pessoas da população geral, estudantes de Enfermagem e de Psicologia. Os resultados, acima descritos, mostraram-se satisfatórios para a consecução de tal objetivo. Contudo, todas as amostras aqui consideradas foram de conveniência, o que restringe a generalização dos resultados. Além disso, esse aspecto também limitou a realização de análises mais detalhadas, como, por exemplo, a identificação da importância relativa das categorias tanto intra-grupo, como intergrupos. Não obstante ser uma pesquisa exploratória e sem a pretensão de ser conclusiva, buscou-se fazer um levantamento geral de elementos envolvidos na maneira de perceber o psicólogo. Contudo, os resultados aqui expostos se alinham com o de estudos anteriores (Gomes \& cols., 1996; Santos, 1989, Weber $\&$ cols., 1994) o que leva a crer na relativa consistência dos achados aqui apresentados.

De acordo com os resultados tem-se que os três grupos enfatizaram o psicólogo como alguém que fornece um auxílio, notadamente de cunho psicológico. As palavras que melhor especificavam a natureza desse auxílio estavam relacionadas a um maior nível de exposição de informações acerca da Psicologia. Assim, o grupo dos estudantes de Psicologia, seguido pelos de Enfermagem foram mais específicos ao tratarem desse auxílio em comparação com o público em geral.

Outra evidência dessa relação entre maior nível de informação e maior acurácia na identificação de elementos propriamente psicológicos foram as categorias Elementos Relacionais Gerais Difusos, presente no grupo das pessoas da população geral, e Elementos Relacionais Gerais, observada no grupo dos estudantes de Enfermagem. Na primeira categoria, agruparam-se palavras que poderiam ser vagamente associadas ao psicólogo, já na segunda, os termos são mais próximos do universo da Psicologia e do psicólogo. No caso do grupo dos estudantes de Psicologia não há nenhuma categoria correspondente a essas duas, pois todas eram compostas por termos semanticamente bem próximos e explicitamente relacionados, o que denota maior coerência na compreensão do psicólogo em relação aos demais grupos.

Uma característica também marcante em todos os grupos foi a alusão do psicólogo enquanto um profissional de saúde mental, demonstrando certa identificação dele com a figura do médico. É culturalmente comum, no Brasil, as pessoas referirem-se a médicos, dentistas, fisioterapeutas e também psicólogos chamando-os de "doutores". Ao que parece, as pessoas tenderiam a perceber a Psicologia como uma área ou especialidade da Medicina e o psicólogo como uma espécie de "médico da mente". Seria interessante em estudos futuros explorar se as pessoas da população geral fariam uma distinção clara entre o psicólogo e o psiquiatra. Com relação aos estudantes de Enfermagem, parece ter havido uma aproximação da Psicologia com o modelo psiquiátrico sem, contudo, ter sido feita uma arbitrária identificação do médico com o psicólogo. Por outro lado, os estudantes de Psicologia apresentaram termos que denotavam adequadamente uma idéia de psicólogo enquanto um promotor de saúde mental. Não há dúvida de que uma das funções mais prementes da Psicologia seja a promoção de saúde. Todavia, a saliência dessa percepção deve-se grandemente ao intenso predomínio na atualidade do modelo clínico vigente na Psicologia brasileira (CFP, 2004; Dimenstein, 2000).

A clara identificação do psicólogo enquanto profissional foi um dos aspectos positivos igualmente observados em todos os grupos. No caso dos estudantes de Psicologia, particularmente, verificou-se a evidência da identificação profissional, quando a palavra $e u$ agrupou-se com as palavras profissão/profissional. Essa unânime referência reflete o explíci- 
to reconhecimento do psicólogo enquanto um profissional capacitado e formado para atuar em um campo específico. Isso, a uma análise menos atenta, poderia soar como óbvio, entretanto, se for considerado que a Psicologia formalmente reconhecida como profissão no Brasil não chega a ter 50 anos esse unânime reconhecimento é indicativo de uma positiva e eficaz consolidação sua no cenário nacional.

No que tange às particularidades ocorridas nos grupos, uma categoria observada apenas no da população geral merece destaque; trata-se da que indicava a ausência de conhecimentos acerca do psicólogo. Apesar da grande difusão da Psicologia, os serviços do psicólogo ainda estão, em termos práticos, bastante restritos a uma pequena parcela da população. Esse acesso limitado associado à pouca divulgação da categoria por parte de suas entidades de classe podem ser os responsáveis pelo impedimento de maior disposição informacional acerca do psicólogo e da Psicologia, o que se constitui num desafio a ser enfrentado.

No grupo dos estudantes universitários emergiu outra categoria exclusiva que também merece destaque; a Humano/Humanismo que reflete uma atenção ou cuidado com os aspectos humanitários da prática profissional do psicólogo. Esse zelo, oriundo provavelmente da formação acadêmica desse grupo, é coerente com uma valorização de aspectos morais e éticos que devem ser atendidos no exercício da profissão, algo semelhante ao observado por Bettoi e Simão (2002).

Similarmente às evidências apresentadas por Gomes e cols. (1996), os estudantes de Psicologia, mais que os outros grupos, coerentemente, tinham uma visão mais próxima das práticas efetivamente realizadas pelos psicólogos. Muito embora essa visão não tenha sido tão abrangente quanto se poderia esperar.

De modo geral, em todos os grupos constataram-se omissões. Como em estudos prévios (Santos, 1989; Weber \& cols, 2004), diversas áreas da Psicologia não foram contempladas. Nenhuma menção explícita foi feita sobre a atuação do psicólogo em contextos, como por exemplo, o educacional, o do trabalho, o jurídico, o penitenciário e tantos outros. Em resumo, a percepção geral de todos os grupos esteve pautada numa visão do psicólogo enquanto um pro- fissional de promoção da saúde mental é que está apto a também oferecer um apoio de cunho psicológico. Esta visão não é incorreta, não obstante deixa de prestigiar outros ramos de atuação. Identificar essa insuficiência é um primeiro passo no sentido de fazer com que as possibilidades de atuação dos profissionais da Psicologia sejam melhor conhecidas e, consequentemente, mais procuradas.

\section{Referências}

Andrade, A. N. \& Morato, H. T. P. (2004). Para uma dimensão ética da prática psicológica em instituições. Estudos de Psicologia, v.9, n.2, 345-353.

Bettoi, W. \& Simão, L. M. (2002). Entrevistas com profissionais como atividade de ensino-aprendizagem desejável na formação do psicólogo. Psicologia: Reflexão e Crítica, v.15, n.3, 613-624.

Castro, P. F. (1999). Reflexões em psicologia e ciência: uma análise da pesquisa aplicada à psicologia clínica. Psicologia: Teoria e Prática, v.1, n.1, 3-13.

Conselho Federal de Psicologia (2004). Pesquisa de opinião com psicólogos inscritos no Conselho Federal de Psicologia. Relatório on-line. Obtido em 20 de março de 2006, de http://www.pol.org.br/ publicacoes/pdf/Pesquisa IBOPE.pdf.

Dimenstein, M. (2000). A cultura profissional do psicólogo e o ideário individualista: implicações para a prática no campo da assistência pública à saúde. Estudos de Psicologia, v.5, n.1, 95-121.

Gomes, W. B., Teixeira, M. A. P., Crescente, D. B., Fachel, J., Sehn, L. \& Klarmann, P. (1996). Atitudes e crenças de estudantes universitários sobre psicoterapia e psicólogos. Psicologia: Ciência e Profissão, v.12, n.2, 121-127.

Magalhães, M. O., Straliotto, M., Keller, M. \& Gomes, W. B. (2001). Eu quero ajudar as pessoas: a escolha vocacional da Psicologia: Psicologia Ciência e Profissão, v.21, n.20,10-27.

Mello, S. L. (1975). Psicologia e profissão em São Paulo. São Paulo: Ática.

Netto, S. P. A. (2004). Psicologia no Brasil. Em M. A. M. Antunes (Org.), História da psicologia no Brasil - Primeiros ensaios. (pp. 139-174). Rio de Janeiro: EdUERJ. 
Pereira, F. M. \& Neto, A. P. (2003). O psicólogo no Brasil: notas sobre seu processo de Profissionalização. Psicologia em Estudo, v.8, n.2, 19-27.

Santos, M. A. (1989). O psicólogo: atuação profissional e função social segundo a percepção de estudantes de Psicologia. Estudos de Psicologia, v.6, n.1, 5-30.

Weber, L. N. D., Rickli, A. \& Liviski, J. D. (1994). Atuação e formação do psicólogo como fatores que influenciam a representação social da Psicologia. Psicologia e Argumentos, v. 12, n.15, 71-88.

Yamamoto, O. H., Dantas, C. M. B., Costa, A. L. F., Alverga, A. R., Seixas, P. S. \& Oliveira, I. F. (2003). A profissão de psicólogo no Rio Grande do Norte. Interação em Psicologia, v.7, n.2, 23-30. 